\title{
Clinical and radiographic effects of ascorbic acid-augmented platelet-rich fibrin versus platelet-rich fibrin alone in intra-osseous defects of stage-III periodontitis patients: a randomized controlled clinical trial
}

\author{
Mohamed Talaat Elbehwashy $^{1} \cdot$ Manal Mohamed Hosny $^{1} \cdot$ Ahmed Elfana $^{1} \cdot$ Alaa Nawar $^{2} \cdot$ Karim Fawzy El-Sayed $^{1,3}$ (D)
}

Received: 9 March 2021 / Accepted: 29 March 2021 / Published online: 12 April 2021

(C) The Author(s) 2021

\begin{abstract}
Aim To assess platelet-rich fibrin (PRF) with ascorbic acid (AA) versus PRF in intra-osseous defects of stage-III periodontitis patients.

Methodology Twenty stage-III/grade $\mathrm{C}$ periodontitis patients, with $\geq 3 \mathrm{~mm}$ intra-osseous defects, were randomized into test (open flap debridement (OFD)+AA/PRF; $n=10$ ) and control (OFD+PRF; $n=10)$. Clinical attachment level (CAL; primary outcome), probing pocket depth (PPD), gingival recession depth (RD), full-mouth bleeding scores (FMBS), full-mouth plaque scores (FMPS), radiographic linear defect depth (RLDD) and radiographic defect bone density (RDBD) (secondary-outcomes) were examined at baseline, 3 and 6 months post-surgically.

Results OFD+AA/PRF and OFD+PRF demonstrated significant intragroup CAL gain and PPD reduction at 3 and 6 months $(p<$ 0.001). OFD+AA/PRF and OFD+PRF showed no differences regarding FMBS or FMPS $(p>0.05)$. OFD+AA/PRF demonstrated significant $\mathrm{RD}$ reduction of $0.90 \pm 0.50 \mathrm{~mm}$ and $0.80 \pm 0.71 \mathrm{~mm}$ at 3 and 6 months, while OFD+PRF showed RD reduction of $0.10 \pm 0.77 \mathrm{~mm}$ at 3 months, with an RD-increase of $0.20 \pm 0.82 \mathrm{~mm}$ at $6 \mathrm{months}(p<0.05)$. OFD+AA/PRF and OFD+PRF demonstrated significant RLDD reduction $(2.29 \pm 0.61 \mathrm{~mm}$ and $1.63 \pm 0.46 \mathrm{~mm} ; p<0.05)$ and RDBD-increase $(14.61 \pm 5.39 \%$ and $12.58 \pm 5.03 \% ; \underline{p}>0.05)$. Stepwise linear regression analysis showed that baseline RLDD and FMBS at 6 months were significant predictors of CAL reduction $(p<0.001)$.

Conclusions OFD+PRF with/without AA significantly improved periodontal parameters 6 months post-surgically. Augmenting PRF with AA additionally enhanced gingival tissue gain and radiographic defect fill.

Clinical relevance PRF, with or without AA, could significantly improve periodontal parameters. Supplementing PRF with AA could additionally augment radiographic linear defect fill and reduce gingival recession depth.
\end{abstract}

Keywords Vitamin C · Ascorbic acid · Platelet-rich fibrin · Periodontal regeneration · Periodontitis · Intra-osseous defects

Karim Fawzy El-Sayed

karim.fawzy@gmail.com

1 Oral Medicine and Periodontology Department, Faculty of Dentistry, Cairo University, Al Saraya Str. 11, Manial, Cairo, Egypt

2 Oral and Maxillofacial Radiology Department, Faculty of Dentistry, Cairo University, Giza, Egypt

3 Clinic for Conservative Dentistry and Periodontology, School of Dental Medicine, Christian Albrechts University, Kiel, Germany

\section{Introduction}

Periodontitis is an inflammatory destructive disorder of the periodontal supporting structures, associated with microbial dysbiosis [1]. A successful periodontal treatment aims to regenerate the lost periodontium to its original anatomy and function [2, 3]. Platelet-rich fibrin (PRF) is an easily prepared, autologous natural scaffold, harbouring a multitude of growth/ differentiation factors, including platelet-derived growth factor (PDGF), transforming growth factor- $\beta$ (TGF- $\beta$ ), insulinlike growth factor (IGF), vascular endothelial growth factor 
(VEGF) and fibroblast growth factor- $\beta$ (FGF- $\beta$ ) [4-7], with a potential to promote periodontal repair/regeneration [8]. It has been investigated in combination with open flap debridement (OFD) and with a variety of biomolecules, including statins, metformin, bisphosphonates, and enamel matrix derivatives (EMD), to achieve a sustained release into periodontal defects [9].

Ascorbic acid (AA) is a potent antioxidant biomolecule, with a multitude of positive effects on oral and periodontal health $[10,11]$, on non-surgical periodontal therapy in smokers [12] and on periodontal disease prevention [11]. AA stimulates self-renewal and differentiation of periodontal stem/progenitor cells, boosts their telomerase activity [13], inhibits cellular senescence [14] and enhances pluripotency biomarker expression [15-17]. Yet, little evidence supports the clinical use of AA incorporated into PRF (AA/PRF) in management of intra-osseous periodontal defects.

To the best of our knowledge, this is the first randomized clinical trial conducted to evaluate clinical attachment level (primary outcome), probing pocket depth, gingival recession depth, full-mouth bleeding scores, full-mouth plaque scores, radiographic defect bone density and radiographic linear defect depth (secondary outcomes), following the application of AA/PRF versus PRF with OFD in intra-osseous defects of stage-III grade $\mathrm{C}$ periodontitis patients.

\section{Materials and methods}

\section{Study design and registration}

The study was designed as double-blind, parallel arms, randomized controlled clinical trial, with 1:1 allocation ratio to compare clinical and radiographic parameters of OFD with AA incorporated into PRF (OFD+AA/PRF; test group) versus PRF alone (OFD+PRF; control group) in intra-osseous defects' therapy. The research protocol was registered on www.clinicaltrials.gov on October 2018 (NCT03707483). Research protocol and informed consent templates were approved by the Ethics Committee, Faculty of Dentistry, Cairo University on December 2018 (IRB:18|12|13). The study was carried out and reported in compliance with the EQUATOR guidelines and ethical principles of the Helsinki Declaration for medical research involving human subjects as revised in Fortaleza 2013.

\section{Participants}

Recruiting potential participants was carried out through screening of patients admitted to the Department of Oral Medicine and Periodontology at the Faculty of Dentistry, Cairo University, Egypt, personal referral and poster announcements, until achieving the targeted sample size adjusted for possible dropouts. Participants were screened, operated and followed up from March 2019 till June 2020. All participants were stage-III grade $\mathrm{C}$ periodontitis patients with mandibular molar teeth showing no mobility nor furcation involvement, with $\geq 5 \mathrm{~mm}$ clinical attachment loss and $\geq$ $3 \mathrm{~mm}$ two- or three-walled intra-osseous defects of as detected radiographically. For grading, the percentage of bone loss was used at the worst affected tooth in the dentition divided by the patient's age [18]. Only motivated adult participants (age $\geq$ 18 ), presented with full-mouth bleeding or plaque scores $\leq$ $20 \%$ at the time of surgical interventions [19], were included. Smokers, diabetic patients, patients with systemic conditions contradicting surgical intervention and pregnant or nursing women were excluded (Fig. S1).

\section{Sample size}

Sample size was calculated using a mean CAL difference of $1 \mathrm{~mm}$ as the minimum clinically acceptable value and a standard deviation of $0.68 \mathrm{~mm}$ [20]. Using $\beta=80 \%$ and $\underline{\alpha}=5 \%$, and based on independent $t$-test, 8 defects were deemed necessary in each group (PS 3.1.2, Vanderbilt University, Tennessee, USA). This number was increased to 10 defects/ group to compensate for $20 \%$ anticipated dropouts during follow-up.

\section{Randomization}

Intra-osseous defects were randomly assigned to be treated using OFD+AA/PRF or OFD+PRF with a 1:1 allocation ratio. Sequence generation and concealment were carried out by a single investigator (MH), using www.random.org. Allocation was concealed in serially numbered, identical and opaque sealed envelopes. KFE was responsible for assigning participants to the corresponding group. All participants were enrolled and equally prepared for the surgical procedure by a single investigator (ME). Following OFD, the allocation was revealed (KFE) to the operator (ME) according to the sequence.

\section{Blinding}

Study participants were blinded. The operator couldn't be blinded. Outcomes' assessors and biostatistician were blinded. Participants' identity and their corresponding study group were masked by assigning an identification number to data files for data transfer to and from assessors.

\section{Outcomes}

Clinical attachment level (CAL, primary outcome) from cementoenamel junction (CEJ) to base of pocket, gingival recession depth $(\mathrm{RD})$ from CEJ to gingival margin and probing pocket depth (PPD) from gingival margin to base of 
pocket [21] were measured at baseline, 3 and 6 months for six sites per tooth, and the highest value was chosen for analysis [22]. Full-mouth bleeding score (FMBS) [23] and full-mouth plaque score (FMPS) [24] were measured at baseline and 6 months post-surgically. Measurements were taken using a Williams graduated periodontal probe (Martin ${ }^{\mathrm{TM}}$ periodontal probe No. 43-357-00, KLS Martin, Tuttlingen, Germany). Changes were calculated by subtracting 3 and 6 months from baseline values, and percentage changes were obtained by dividing change values by baseline numbers.

Radiographic linear defect depth (RLDD; secondary outcome) was measured as the depth of intra-osseous defect from alveolar crest (AC) to defect base (DB) at baseline and 6 months. Customized bite blocks were fabricated for each site, using diagnostic casts and acrylic resin. Using XCP X-ray Holder kit (Dentsply Sirona, Charlotte, USA) and PSP sensor size two (Xios AE, Dentsply Sirona), parallel-angel standardized radiographs were obtained $(60 \mathrm{kVp}, 8 \mathrm{~mA}$, and $0.10 \mathrm{~s}$, Heliodent Plus, Dentsply Sirona). Using ImageJ software (Research Services Branch, NIH, Bethesda, Maryland, USA), three reference points relevant to each defect site, namely, CEJ, AC and DB, and three reference lines, the long axis of the concerned tooth, a line parallel to the root surface from $\mathrm{CEJ}$ to $\mathrm{DB}$, and another starting from $\mathrm{AC}$ ending perpendicularly on the long axis line, were identified. Radiographic linear defect depth (RLDD) was measured over the DB-CEJ line on baseline and follow-up radiographs as the distance from DB to the intersection point with the line between $\mathrm{AC}$ and the long axis line [25]. Defect angle at baseline was determined as the angle between lines connecting CEJ to DB and lateral defect border [26] (Fig. 1).

For radiographic defect bone density (RDBD; secondary outcome) assessment, the region of interest (ROI) was outlined, through drawing an outline corresponding to the demarcating walls of the intra-osseous defect, and mean grey values were calculated. ROIs were not superimposed on any portion of the tooth surface. The measured area customized for each baseline radiograph was duplicated on the 6-month radiographs, and grey value changes were calculated [27].

\section{Calibration}

Outcomes were recorded by two blinded calibrated investigators, one for clinical parameters (AE) and the other for radiographic measures (AN). Calibration was done before study conduction by measuring relevant data (not included in the study) twice 1 week apart. All measurements were repeated, retrieving intra-examiner agreement scores of 0.85 for CAL, $\mathrm{PPD}$ and $\mathrm{RD}$ and 0.82 for radiographic measurements.

\section{Preoperative phase}

Participants meeting all inclusion criteria proceeded to radiographic examination were provided with information about the study, undersigned an informed consent, received phaseI periodontal therapy of supra- and subgingival debridement and were instructed to maintain proper oral hygiene by teeth brushing and daily use of $0.12 \%$ chlorhexidine HCL mouthwash (Hexitol, ADCO Pharma Co, Cairo, Egypt) [28]. After 4-6 weeks, re-evaluation was performed to confirm the need for periodontal surgery (persistence of interproximal defect with $P P D \geq 5 \mathrm{~mm}$, clinical attachment loss $\geq 5 \mathrm{~mm}$ and radiographic intra-osseous defect $\geq 3 \mathrm{~mm}$ ) [29].

\section{Surgical phase}

All surgeries were conducted by a single operator (ME). On the day of surgery (baseline) FMPS, FMBS, CAL, PPD and $\mathrm{RD}$ were recorded and standardized periapical radiographs were taken. A full-thickness mucoperiosteal flap was raised, around the affected tooth and one adjacent tooth mesial and distal using 15C surgical blades (KLS Martin GmbH, Tuttlingen, Germany). Thorough OFD the defects were instrumented, using mini-five and after-five Gracey curettes $(\mathrm{Hu}-$
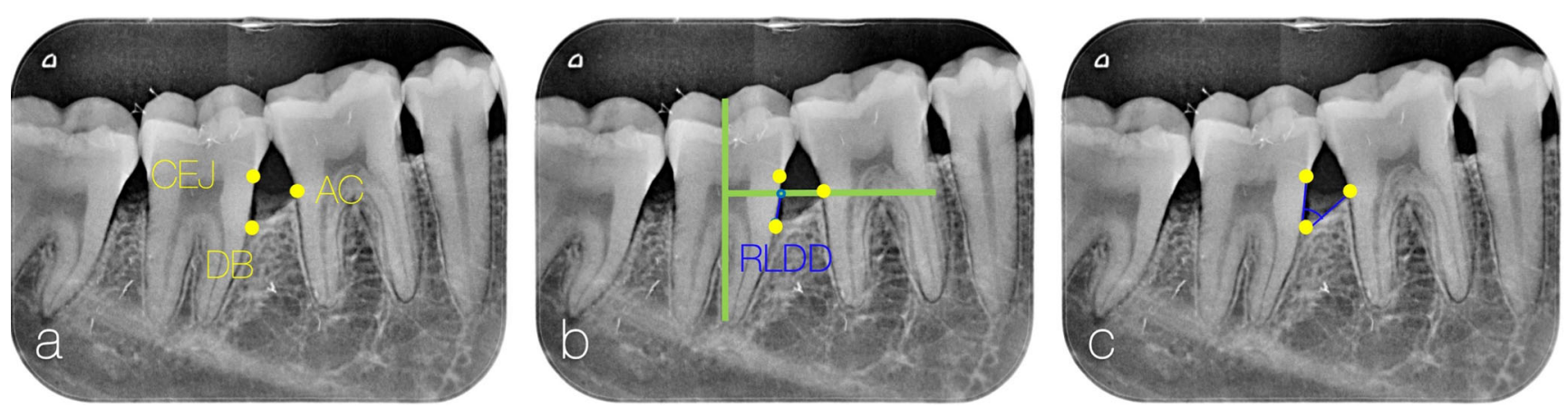

Fig. 1 Intra-osseous defect radiographic measurements. a Identifying reference points: cementoenamel junction (CEJ), defect base (DB) and alveolar crest (AC). b Identifying reference lines (in green): vertical line corresponding to long axis and horizontal perpendicular line passing through AC, and identifying radiographic linear defect depth (RLDD) in blue. $\mathbf{c}$ Radiographic angle connecting CEJ, DB and the lateral border of the defect 
Friedy, Chicago, USA) under local anesthesia (2\% mepivacaine $\mathrm{HCl}$ with 1:20000 levonordefrin, Alexandria Co. for Pharmaceuticals, Egypt).

For PRF preparation, $10 \mathrm{~mm}$ of fresh blood was drawn by venipuncture of the antecubital vein and collected into a blood collection tube without anticoagulant. In the AA/OFD+PRF group, $2500 \mu \mathrm{g}$ pure AA (Redox-C, BAYER, Istanbul, Turkey) was added to the fresh blood to achieve a concentration of $250 \mu \mathrm{g} / \mathrm{ml} \mathrm{AA}$ [15-17], and the tube was centrifuged at $400 \mathrm{~g}$ (3000 rpm) for $10 \mathrm{~min}$ at room temperature as described before [30]. The resultant PRF clot was compressed between two sterile gauze pieces and placed into the intra-osseous defect [31]. Flaps were repositioned and secured with 5-0 internal vertical mattress sutures (ASSUT, Pully-Lausanne, Switzerland, Fig. 2).

\section{Postoperative care and follow-up}

1g E-moxclav ( $875 \mathrm{mg}$ amoxicillin $+125 \mathrm{mg}$ clavulanic acid, EIPICO, Tenth of Ramadan, Egypt) was administrated orally twice/day for 6 days. Participants were instructed to avoid hard brushing or trauma to the surgical site for 4 weeks, during which plaque was controlled by prescribing $0.12 \%$ chlorhexidine HCL oral rinse (Hexitol, ADCO Pharma Co, Cairo, Egypt) twice daily for $1 \mathrm{~min}$ [32]. Sutures were removed 14 days following surgery. Participants were instructed to continue tooth cleaning, using an ultra-soft toothbrush and roll technique for 1 month, and then resume normal brushing using a soft toothbrush. Professional plaque control was done monthly for 6 months [33].

\section{Statistical analysis}

Data was explored for normality, using Kolmogorov-Smirnov and Shapiro-Wilk tests. Chi-square and Fisher's exact tests were used for categorical baseline data. Numerical data were presented as means and standard deviation (SD). Both treatment groups were compared, using an independent Student's $t$-test. Mean difference and 95\% confidence interval (95\% CI) were stated for each comparison. For intragroup comparisons, repeated measure ANOVA with Bonferroni correction was used for RLDD, FMBS and FMPS, a paired $t$-test was used. Additionally, a stepwise linear regression model was constructed, using CAL gain after 6 months as the dependent variable, while study group, age, gender, number of defect walls, FMBS at baseline, FMBS at 6 months, FMPS at baseline, FMPS at 6 months, radiographic angle and RLDD at baseline were the independent variables. All tests were two-tailed and $p<0.05$ was considered statistically significant (SPSS for Windows, version 26, IBM, New York, USA).

\section{Results}

\section{Baseline characteristics}

This randomized, parallel-group clinical trial included a total of 20 intra-osseous defects in 20 participants ( 3 males and $17 \mathrm{fe}-$ males) diagnosed with stage-III grade $\mathrm{C}$ periodontitis. The $\mathrm{OFD}+$ PRF group included 1 male and 9 females with a mean $( \pm \mathrm{SD})$ age of $28.2 \pm 5.63$ years, while the OFD+AA/PRF group included 2 males and 8 females ( $32 \pm 5.27$ years). The study was completed with no loss to follow-up. No unexpected adverse events were noticed clinically or reported by participants, such as allergy, abscess or surgical site exposure, and the healing processes were uneventful. Distribution of age and gender was balanced between test and control $(p>0.05)$. OFD+AA/PRF group contained 50\% combined one-two-wall, $40 \%$ two-wall and $10 \%$ combined two-three-wall defects, while OFD+PRF group comprised $60 \%$ two-wall, $30 \%$ three-wall and $10 \%$ combined twothree-wall defects ( $p=0.038$, Chi-square). Baseline defect angle showed means of $44.68^{\circ} \pm 4.39^{\circ}$ and $36.69^{\circ} \pm 6.22^{\circ}$ in OFD+ $\mathrm{AA} / \mathrm{PRF}$ and OFD+PRF, respectively $(p=0.004, t$-test, Table 1$)$.

\section{Clinical attachment level (CAL)}

Statistically significant CAL gain was notable in both groups over time $(p<0.001$, ANOVA/Bonferroni). OFD+AA/PRF showed CAL gain of $4.20 \pm 1.18 \mathrm{~mm}(51.13 \pm 12.70 \%)$ and $4.25 \pm 1.27 \mathrm{~mm}(51.93 \pm 13.91 \%)$, while OFD+PRF demonstrated CAL gain of $4.05 \pm 086 \mathrm{~mm}(55.06 \pm 14.04 \%)$ and $3.90 \pm$ $1.15 \mathrm{~mm}(52.82 \pm 16.07 \%)$ at 3 and 6 months respectively, with no significant differences observed between the groups at 3 and 6 months ( $p \geq 0.05$, independent $t$-test, Table 2).

\section{Probing pocket depth (PPD)}

OFD+AA/PRF showed a significant PPD reduction of $3.30 \pm$ $1.36 \mathrm{~mm}(47.86 \pm 16.77 \%)$ and $3.45 \pm 1.36 \mathrm{~mm}(49.91 \pm$ $14.37 \%$ ), while OFD+PRF demonstrated a significant PPD reduction of $3.95 \pm 0.60 \mathrm{~mm}(57.77 \pm 9.02 \%)$ and $4.10 \pm$ $0.61 \mathrm{~mm}(59.91 \pm 8.89 \%)$ at 3 and 6 months, respectively, with no significant difference observed between the groups at 3 and 6 months ( $p \geq 0.05$, independent $t$-test, Table 2).

\section{Recession depth (RD)}

In OFD+AA/PRF, a significant RD reduction of $0.90 \pm$ $0.74 \mathrm{~mm}$ and $0.80 \pm 0.74 \mathrm{~mm}$ was notable at 3 and 6 months, respectively $(p=0.003)$, while $\mathrm{OFD}+\mathrm{PRF}$ demonstrated a RD reduction of $0.10+0.77 \mathrm{~mm}$ at 3 months with a rebound $\mathrm{RD}$ increase of $0.20 \pm 0.82 \mathrm{~mm}$ at 6 months $(p=0.361$, ANOVA/ Bonferroni). Significant RD reduction in favour of OFD+AA/ PRF was notable at 3 and 6 months $(p=0.029$ and $p=0.010$, respectively, independent $t$-test, Table 2 ). 


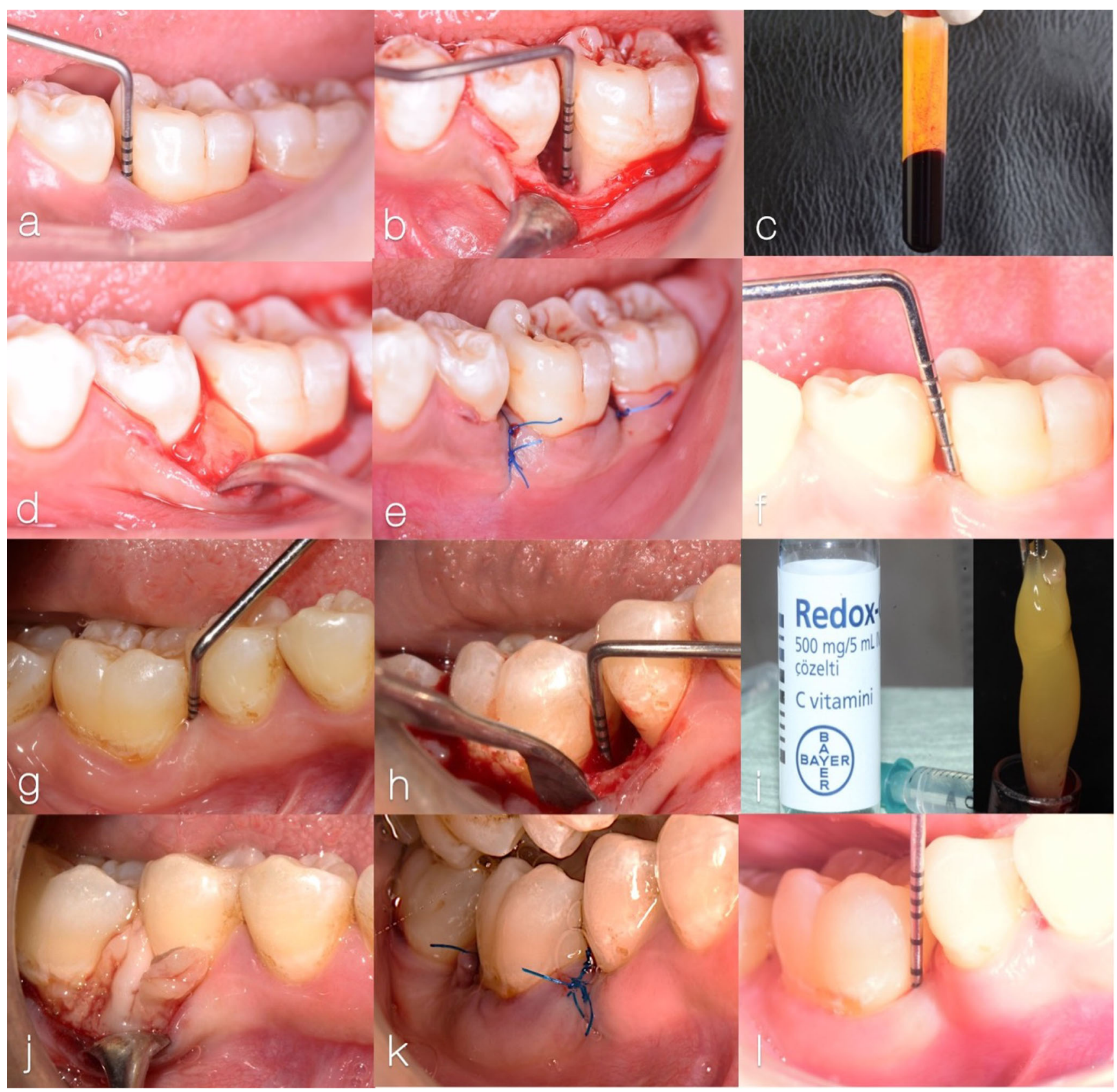

Fig. 2 Clinical steps in representative cases of the control group, using open flap debridement (OFD) and platelet-rich fibrin (PRF) (a-f) and test group using OFD and $\mathrm{AA} / \mathrm{PRF}$ combination [81]: a 7-mm probing pocket depth mesial to lower left six at baseline. b Intra-osseous defect with vertical component of $5 \mathrm{~mm}$. c Preparation of PRF. d Application of PRF plug into the periodontal defect. e Internal vertical mattress sutures.

\section{Full-mouth bleeding (FMBS) and plaque scores (FMPS)}

In OFD+AA/PRF, FMBS was $11.01 \pm 3.25 \%$ and $10.78 \pm$ $2.21 \%$, versus $10.27 \pm 2.46 \%$ and $11.18 \pm 2.54 \%$ in OFD+ PRF at baseline and 6 months, respectively. For FMPS, OFD+ AA/PRF showed $11.72 \pm 2.59 \%$ and $12.36 \pm 2.46 \%$, versus OFD+PRF, which demonstrated $10.89 \pm 2.77 \%$ and $13.20 \pm$ $2.47 \%$ at baseline and 6 months, respectively, without f $3-\mathrm{mm}$ probing pocket depth after 6 months. g $8-\mathrm{mm}$ probing pocket depth mesial to lower right six at baseline. $\mathbf{h}$ Intra-osseous defect with vertical component of $5 \mathrm{~mm}$. i Pure AA vial (left) and AA/PRF (right). $\mathbf{j}$ Application of the AA/PRF plug into the periodontal defect. $\mathbf{k}$ Internal vertical mattress suture. $12-\mathrm{mm}$ probing pocket depth after 6 months

significant differences either within ( $p \geq 0.05$, paired $t$-test) or between groups ( $p \geq 0.05$, independent $t$-test, Table 2).

\section{Radiographic linear defect depth (RLDD) and radio- graphic defect bone density (RDBD)}

Both OFD+AA/PRF and OFD+PRF demonstrated a statistically significant RLDD reduction at 6 months compared to 
Table 1 Participant's baseline parameters and distribution and configuration of intra-osseous defects (significant differences are marked with asterisk; $* p<0.05$ )

\begin{tabular}{lcll}
\hline & $\begin{array}{l}\text { OFD+AA/PRF } \\
n=10\end{array}$ & $\begin{array}{l}\text { OFD+PRF } \\
n=10\end{array}$ & $p$ Value \\
\hline $\begin{array}{l}\text { Age in years [mean (SD)] } \\
\text { Gender }\end{array}$ & $32( \pm 5.27)$ & $28.2( \pm 5.63)$ & 0.137 \\
Male [n (\%)] & $2(20 \%)$ & $1(10 \%)$ & 1.00 \\
Female [n(\%)] & $8(80 \%)$ & $9(90 \%)$ & \\
Distribution of teeth with defects & & \\
Anterior [n(\%)] & $5(50 \%)$ & $2(20 \%)$ & 0.371 \\
Premolar [n(\%)] & $2(20 \%)$ & $3(30 \%)$ & \\
Posterior [n (\%)] & $3(30 \%)$ & $5(50 \%)$ & \\
Morphology of intra-osseous defects & & \\
Combined 1-2 walls $[n(\%)]$ & $5(50 \%)$ & $0(0 \%)$ & \\
2 walls $[n(\%)]$ & $4(40 \%)$ & $6(60 \%)$ & $0.038^{*}$ \\
Combined 2-3 walls $[n(\%)]$ & $1(10 \%)$ & $1(10 \%)$ & \\
3 walls $[n(\%)]$ & $0(0 \%)$ & $3(30 \%)$ & \\
Intra-osseous defect angle & $44.68^{\circ}( \pm 4.39)$ & $36.69( \pm 6.22)$ & $0.004^{*}$ \\
\hline
\end{tabular}

baseline ( $p \leq 0.001$, paired $t$-test). A mean RLDD reduction of $2.29 \pm 0.61 \mathrm{~mm}(48.30 \pm 8.30 \%)$ was demonstrated in OFD+ AA/PRF, while OFD+PRF showed $1.63 \pm 0.46 \mathrm{~mm}(40.62 \pm$ $9.59 \%)$ reduction at 6 months $(p=0.014)$. OFD+AA/PRF and OFD+PRF exhibited an increase in RDBD of $14.61 \pm 5.39 \%$ and $12.58 \pm 5.03 \%$ at 6 months $(p=0.395$, independent $t$-test, Table 3).

\section{Stepwise linear regression analysis}

Stepwise linear regression analysis showed a direct correlation between RLDD at baseline and CAL gain $(p<0.001)$ as well as an inverse correlation between FMBS at 6 months and CAL gain $(p=0.023$, Table 4$)$.

\section{Discussion}

Periodontitis is a chronic multifactorial inflammatory disease, affecting the teeth supporting structures [1], causing alveolar bone destruction with horizontal and vertical bony defects. These intra-osseous defects are often associated with deep residual pockets, worsening the teeth long-term prognosis $[29,34,35]$. Periodontal therapy of intra-osseous defects aims to restore the lost periodontal structures, prevent the progression of periodontal destruction and enhance the tooth prognosis [36]. In the present study, the effect of AA augmented PRF was clinically investigated for the first time in the OFD of periodontitis-induced intra-osseous defects.
OFD remains to be one of the evidence-based periodontal surgical techniques [37, 38] for surgical therapy of intraosseous defects [29] with remarkable results [39, 40]. Sites included in the current study presented with $\geq 5 \mathrm{~mm}$ clinical attachment loss and $\geq 3 \mathrm{~mm}$ three or two walls, or combined intra-osseous defects [41, 42]. Having almost identical molecular weights, the incorporation of AA into the PRF plugs relied on a previously reported method for metronidazole inclusion into PRF [30]. The employed PRF spin protocol was comparable to previous studies, exploring the effect of PRF combined with a variety of biological agents [26, 43-47] and using the same spin protocol. A split-mouth design was avoided to exclude any systemic effects of the applied AA on the control group, through the individual's circulation. Comparable to earlier clinical trials on PRF, a 6-month follow-up period was selected [26, 48-54]. Smokers were excluded to avoid the retarding effect of smoking on periodontal wound healing [55].

Four prerequisites are pivotal to achieve periodontal repair/ regeneration, namely, the cells, the adequate blood supply, the suitable scaffold directing the repair/regeneration process and finally the signaling biomolecules, modulating the cellular activities [56-58]. Aside from the physical properties of the defect-filling PRF haemostatic plug, platelets stimulate the proliferation and activation of a variety of cells involved in the repair/regeneration process, in addition to the release of a variety of growth, adhesion, coagulation and angiogenic factors into the defect site [59]. Through its fibrin content, the PRF plug could further provide a three-dimensional structural framework for regenerating periodontal cells [60].

In line with the current investigation, previous randomized controlled trials demonstrated the efficacy of PRF with OFD in achieving remarkable periodontal repair of intra-osseous defects [47, 61-64]. PRF with OFD could improve CAL, PPD and radiographic defect fill comparable or even superior to OFD in combination with bone grafts [65]. An incorporation of regenerative biomolecules into the PRF could further augment these effects [9]. Thus, PRF has been utilized as an autologous carrier for local delivery EMD, growth and morphogenetic/angiogenic factors, antibiotics and antiosteoporotic molecules [26, 30, 66]. Through its degradation process, PRF could provide a gradual release of the incorporated biomolecules over 10-14 days [66], with superior results in the treatment of periodontal intra-osseous defects [67, 68]. At $250 \mu \mathrm{g} / \mathrm{ml}$, AA was noted to maximally stimulate the proliferation, pluripotency and differentiation of gingival mesenchymal stem/progenitor cells (G-MSCs) $[16,17]$. Thus, in the current study AA was incorporated in the PRF in the above concentration and introduced for sustained-release into the intra-osseous defects, to exploit these cellular reparative/ regenerative attribute-boosting effects on the resident periodontal stem/progenitor as well as differentiated cells during the surgical wound healing. 
Table 2 Mean $( \pm \mathrm{SD})$, mean difference [95\% CI] for clinical attachment level (CAL), probing pocket depth (PPD), recession depth (RD), full-mouth bleeding scores (FMBS) and full-mouth plaque scores (FMPS) (significant differences are marked with asterisk; * $p<0.05$, CI: confidence interval)

\begin{tabular}{|c|c|c|c|c|}
\hline & $\begin{array}{l}\text { OFD+AA/PRF } \\
\text { Mean }( \pm \mathrm{SD}) \\
n=10\end{array}$ & $\begin{array}{l}\text { OFD+PRF } \\
\text { Mean }( \pm \mathrm{SD}) \\
n=10\end{array}$ & $\begin{array}{l}\text { Mean difference } \\
{[95 \% \mathrm{CI}]}\end{array}$ & Intergroup $p$ value \\
\hline \multicolumn{5}{|l|}{ Clinical attachment level (CAL) } \\
\hline Baseline (mm) & $8.25( \pm 1.50)$ & $7.45( \pm 0.86)$ & $0.80[-0.35,1.95]$ & 0.160 \\
\hline At 3 months (mm) & $4.05( \pm 1.34)$ & $3.40( \pm 1.20)$ & $0.65[-0.55,1.85]$ & 0.268 \\
\hline At 6 months $(\mathrm{mm})$ & $4.00( \pm 1.55)$ & $3.55( \pm 1.32)$ & $0.45[-0.90,1.90]$ & 0.493 \\
\hline Intragroup $p$ value & $<0.001 *$ & $<0.001 *$ & & \\
\hline Gain at 3 months (mm) & $4.20( \pm 1.18)$ & $4.05( \pm 0.86)$ & $0.15[-0.82,1.12]$ & 0.750 \\
\hline Gain at 3 months (\%) & $51.13( \pm 12.70)$ & $55.06( \pm 14.04)$ & $-3.93[-16.51,8.65]$ & 0.520 \\
\hline Gain at 6 months (mm) & $4.25( \pm 1.27)$ & $3.90( \pm 1.15)$ & $0.35[-0.79,1.49]$ & 0.527 \\
\hline Gain at 6 months $(\%)$ & $51.93( \pm 13.91)$ & $52.82( \pm 16.07)$ & $-0.89[-14.67,12.88]$ & 0.893 \\
\hline \multicolumn{5}{|l|}{ Probing pocket depth (PPD) } \\
\hline Baseline (mm) & $6.80( \pm 1.36)$ & $6.90( \pm 0.97)$ & $-0.10[-1.21,1.01]$ & 0.852 \\
\hline At 3 months (mm) & $3.50( \pm 1.18)$ & $2.95( \pm 0.86)$ & $0.55[-0.43,1.53]$ & 0.250 \\
\hline At 6 months (mm) & $3.35( \pm 1.36)$ & $2.80( \pm 0.86)$ & $0.55[-0.35,1.45]$ & 0.217 \\
\hline Intragroup $p$ value & $<0.001 *$ & $<0.001 *$ & & \\
\hline Reduction at 3 months (mm) & $3.30( \pm 1.36)$ & $3.95( \pm 0.60)$ & $-0.65[-1.64,0.34]$ & 0.183 \\
\hline Reduction at 3 months (\%) & $47.86( \pm 16.77)$ & $57.77( \pm 9.02)$ & $-9.91[-22.57,2.74]$ & 0.117 \\
\hline Reduction at 6 months (mm) & $3.45( \pm 1.36)$ & $4.10( \pm 0.61)$ & $-0.65[-1.64,0.34]$ & 0.186 \\
\hline Reduction at 6 months (\%) & $49.91( \pm 14.37)$ & $59.91( \pm 8.89)$ & $-10.00[-21.23,1.22]$ & 0.077 \\
\hline \multicolumn{5}{|l|}{ Recession depth (RD) } \\
\hline Baseline (mm) & $1.45( \pm 0.76)$ & $0.55( \pm 0.55)$ & $0.90[0.28,1.52]$ & $0.007 *$ \\
\hline At 3 months (mm) & $0.55( \pm 0.69)$ & $0.45( \pm 0.64)$ & $0.10[-0.52,0.72]$ & 0.740 \\
\hline At 6 months (mm) & $0.65( \pm 0.82)$ & $0.75( \pm 0.68)$ & $-0.10[-0.81,0.61]$ & 0.769 \\
\hline Intragroup $p$ value & $0.003 *$ & 0.361 & & \\
\hline Reduction at 3 months (mm) & $0.90( \pm 0.74)$ & $0.10( \pm 0.77)$ & $0.80[-0.09,1.51]$ & $0.029 *$ \\
\hline Reduction at 6 months (mm) & $0.80( \pm 0.71)$ & $-0.20( \pm 0.82)$ & $1.00[0.28,1.72]$ & $0.010^{*}$ \\
\hline \multicolumn{5}{|c|}{ Full-mouth bleeding score (FMBS) } \\
\hline Baseline & $11.01( \pm 3.25)$ & $10.27( \pm 2.46)$ & $0.74[-1.96,3.45]$ & 0.571 \\
\hline 6 months & $10.78( \pm 2.21)$ & $11.18( \pm 2.54)$ & $-0.40[-2.63,1.84]$ & 0.715 \\
\hline Intragroup $p$ value & 0.880 & 0.333 & & \\
\hline \multicolumn{5}{|l|}{ Full-mouth plaque score (FMPS) } \\
\hline Baseline & $11.72( \pm 2.59)$ & $10.98( \pm 2.77)$ & $0.74[-1.78,3.26]$ & 0.546 \\
\hline 6 months & $12.63( \pm 2.46)$ & $13.20( \pm 2.47)$ & $-0.57[-2.88,1.75]$ & 0.614 \\
\hline Intragroup $p$ value & 0.456 & 0.124 & & \\
\hline
\end{tabular}

The stepwise linear regression analysis demonstrated that irrespective of the treatment group, RLDD at baseline and FMBS after 6 months were significant predictors of CAL gain. This underlines the importance of an inflammation-free periodontium during the healing phase for an enhanced $\mathrm{CAL}$ gain. In the present investigation, patients were instructed into regular tooth brushing, and professional plaque control was conducted monthly during the study period, to ensure a plaque- and inflammation-free periodontium. Both OFD+ $\mathrm{AA} / \mathrm{PRF}$ and $\mathrm{OFD}+\mathrm{PRF}$ demonstrated statistically significant CAL gain and PPD reduction at 6 months, in dimensions comparable to a previous study on EMD+PRF in the treatment of intra-osseous defects [26]. Yet, gingival recession depth reduction and radiographic intra-osseous depth fill were significantly superior in the OFD+AA/PRF group. These findings could be explained by the additive role of AA to the PRF, boosting cellular pluripotency, proliferative and regenerative attributes of stem/progenitor cells, osteoblasts, fibroblasts [69, $70]$ and G-MSCs [16, 17]; its ability to increase extracellular matrix production [71]; the collagen biosynthesis of the periodontal ligament, gingiva, cement and alveolar bone [72, 73]; and the expression of alkaline phosphatase and osteocalcin 
Table 3 Changes in mean $( \pm \mathrm{SD})$ for radiographic linear defect depth (RLDD) and radiographic defect bone density (RDBD)

\begin{tabular}{|c|c|c|c|c|}
\hline & $\begin{array}{l}\text { OFD+AA/PRF } \\
\text { Mean }( \pm \text { SD })\end{array}$ & $\begin{array}{l}\text { OFD+PRF } \\
\text { Mean }( \pm \text { SD })\end{array}$ & $\begin{array}{l}\text { Mean difference } \\
{[95 \% \mathrm{CI}]}\end{array}$ & Intergroup $p$ value \\
\hline \multicolumn{5}{|l|}{ Defect depth (RLDD) } \\
\hline At baseline $(\mathrm{mm})$ & $4.69( \pm 0.76)$ & $3.98( \pm 0.43)$ & $0.71[0.12,1.30]$ & $0.022 *$ \\
\hline At 6 months $(\mathrm{mm})$ & $2.40( \pm 0.45)$ & $2.35( \pm 0.42)$ & $0.05[-0.36,0.46]$ & 0.817 \\
\hline Intragroup $p$ value & $<0.001 *$ & $<0.001 *$ & & \\
\hline Defect depth reduction after 6 months (mm) & $2.29( \pm 0.61)$ & $1.63( \pm 0.46)$ & $0.66[0.15,1.17]$ & $0.014 *$ \\
\hline Defect depth reduction after 6 months $(\%)$ & $48.30( \pm 8.30)$ & $40.62( \pm 9.59)$ & $7.68[-7.48,16.10]$ & 0.072 \\
\hline Radiographic defect bone density (RDBD) increase (\%) & $14.61( \pm 5.39)$ & $12.58( \pm 5.03)$ & $-2.03[-6.93,2.87]$ & 0.395 \\
\hline
\end{tabular}

Significant differences are marked with asterisk; ${ }^{*} p<0.05$, CI: confidence interval

$[74,75]$ as well as its potential to increase the proliferation of keratinocytes and fibroblasts, improving thereby the gingival phenotype [76, 77].

Still, the present results should be interpreted in light of the current trials' limitations. First, although a 6month follow-up was employed in previous clinical trials on PRF, limiting the current study's follow-up to 6 months was greatly attributed to the fact that patients form lower socio-economic status, who usually visit the outpatient clinic of the Faculty of Dentistry, Cairo University for symptomatic treatment, are not interested to adhere to longer follow-up periods. Second, the preparation and use of a blood-derived product as PRF depends on the patients' acceptance, and hence patients who were afraid of blood sampling refused to participate in the study. Third, the strict inclusion criteria of stage-III grade $\mathrm{C}$ periodontitis patients lengthened the duration for participants' inclusion. Fourth, the current study did not employ the recently developed horizontal centrifugation/preparation protocol, which could have increased the number of platelets and leucocytes in the
PRF plugs, with a more even platelets distribution [78, 79], thereby further improving the PRF's reparative/ regenerative effects. Fifth, although the defects were randomized, more favourable defect morphologies (number of osseous walls and defect angel) were arbitrarily allocated to the control than the test group at baseline, a factor that could have affected the outcome of the interventions $[42,80]$. Finally, no microbiological or biomarkers examinations were carried out, to test the effect of the interventions on the resident periodontal flora.

Within the limitations of the current randomized controlled clinical trial, it can be concluded that both interventions showed significant improvements in clinical and radiographic outcomes 6 months post-surgically. Augmenting PRF with AA resulted in further significant improvement in gingival recession and radiographic defect fill. The results spot the light on a positive impact of AA and PRF in the treatment of periodontitis and the possibility of their combined application in clinical periodontal therapy. Further clinical and histological studies with longer follow-ups and larger sample size are needed to explore their periodontal regenerative potential.
Table 4 Significant predictors of CAL gain according to stepwise linear regression analysis model

\begin{tabular}{llllll}
\hline Variables & $\beta$ & SE & \multicolumn{2}{l}{$95 \% \mathrm{CI}$} & \multirow{2}{*}{$p$ Value } \\
\cline { 5 - 6 } & & & Lower limit & Upper limit & \\
\hline Age & -0.005 & 0.046 & -0.110 & 0.099 & 0.912 \\
Gender & 0.261 & 0.578 & -1.046 & 1.568 & 0.662 \\
Treatment & -0.565 & 0.604 & -1.932 & 0.802 & 0.374 \\
Number of walls in the defect & 0.261 & 0.275 & -0.363 & 0.884 & 0.369 \\
FMBS at baseline & -0.016 & 0.079 & -0.195 & 0.163 & 0.841 \\
FMBS after 6 months & -0.193 & 0.078 & -0.357 & -0.029 & $0.023 *$ \\
FMPS at baseline & -0.100 & 0.092 & -0.308 & 0.108 & 0.305 \\
FMPS at 6 months & -0.108 & 0.118 & -0.375 & 0.158 & 0.383 \\
RLDD at baseline & 1.395 & 0.256 & 0.854 & 1.936 & $<0.001^{*}$ \\
Radiographic defect angle & -0.026 & 0.041 & -0.120 & 0.067 & 0.538 \\
\hline
\end{tabular}

$\beta$ regression coefficient, $S E$ standard error, $C I$ confidence interval, FMBS full-mouth bleeding score, FMPS fullmouth plaque score, $R L D D$ radiographic linear defect depth, significant differences are marked with asterisk; * $p<$ 0.05 
Supplementary Information The online version contains supplementary material available at https://doi.org/10.1007/s00784-021-03929-1.

Acknowledgements The authors thank Dr. Khaled Keraa for his excellent statistical analyses.

Author contribution M.E., A.E., M.H. and K.F.E. conceived the idea and conducted the clinical trial. K.F.E. lead the writing. A.N. conducted the radiographic evaluation.

Funding Open Access funding enabled and organized by Projekt DEAL. The work was supported by the Department of Oral Medicine and Periodontology, Faculty of Dentistry, Cairo University, Egypt.

\section{Declarations}

Ethics approval All procedures performed in studies involving human participants were in accordance with the ethical standards of the institutional and/or national research committee and with the 1964 Helsinki Declaration and its later amendments or comparable ethical standards.

Informed consent Informed consent was obtained from all individual participants included in the study.

Conflict of interest The authors declare no competing interests.

Open Access This article is licensed under a Creative Commons Attribution 4.0 International License, which permits use, sharing, adaptation, distribution and reproduction in any medium or format, as long as you give appropriate credit to the original author(s) and the source, provide a link to the Creative Commons licence, and indicate if changes were made. The images or other third party material in this article are included in the article's Creative Commons licence, unless indicated otherwise in a credit line to the material. If material is not included in the article's Creative Commons licence and your intended use is not permitted by statutory regulation or exceeds the permitted use, you will need to obtain permission directly from the copyright holder. To view a copy of this licence, visit http://creativecommons.org/licenses/by/4.0/.

\section{References}

1. Papapanou PN, Sanz M, Buduneli N, Dietrich T, Feres M, Fine DH, Flemmig TF, Garcia R, Giannobile WV, Graziani F, Greenwell H, Herrera D, Kao RT, Kebschull M, Kinane DF, Kirkwood KL, Kocher T, Kornman KS, Kumar PS, Loos BG, Machtei E, Meng H, Mombelli A, Needleman I, Offenbacher S, Seymour GJ, Teles R, Tonetti MS (2018) Periodontitis: Consensus report of workgroup 2 of the 2017 world workshop on the classification of periodontal and peri-implant diseases and conditions. J Periodontol 89(Suppl 1):S173-S182. https:// doi.org/10.1002/JPER.17-0721

2. Nibali L, Koidou VP, Nieri M, Barbato L, Pagliaro U, Cairo F (2020) Regenerative surgery versus access flap for the treatment of intrabony periodontal defects: a systematic review and meta-analysis. $\mathrm{J}$ Clin Periodontol 47(Suppl 22):320-351. https://doi.org/10.1111/ jcpe. 13237

3. Tsai SJ, Ding YW, Shih MC, Tu YK (2020) Systematic review and sequential network meta-analysis on the efficacy of periodontal regenerative therapies. J Clin Periodontol 47(9):1108-1120

4. Kim J, Ha Y, Kang NH (2017) Effects of growth factors from platelet-rich fibrin on the bone regeneration. The Journal of
Craniofacial Surgery 28(4):860-865. https://doi.org/10.1097/SCS. 0000000000003396

5. Masuki H, Okudera T, Watanebe T, Suzuki M, Nishiyama K, Okudera H, Nakata K, Uematsu K, Su CY, Kawase T (2016) Growth factor and pro-inflammatory cytokine contents in plateletrich plasma (PRP), plasma rich in growth factors (PRGF), advanced platelet-rich fibrin (A-PRF), and concentrated growth factors (CGF). Int J Implant Dent 2(1):19. https://doi.org/10.1186/s40729-0160052-4

6. Kobayashi E, Fluckiger L, Fujioka-Kobayashi M, Sawada K, Sculean A, Schaller B, Miron RJ (2016) Comparative release of growth factors from PRP, PRF, and advanced-PRF. Clin Oral Investig 20(9):2353-2360. https://doi.org/10.1007/s00784-016-1719-1

7. Fujioka-Kobayashi M, Miron RJ, Hernandez M, Kandalam U, Zhang Y, Choukroun J (2017) Optimized platelet-rich fibrin with the low-speed concept: growth factor release, biocompatibility, and cellular response. J Periodontol 88(1):112-121. https://doi.org/10. 1902/jop.2016.160443

8. Zhou S, Sun C, Huang S, Wu X, Zhao Y, Pan C, Wang H, Liu J, Li Q, Kou Y (2018) Efficacy of adjunctive bioactive materials in the treatment of periodontal intrabony defects: a systematic review and meta-analysis. Biomed Res Int 2018:8670832-8670815. https://doi. org $/ 10.1155 / 2018 / 8670832$

9. Miron RJ, Moraschini V, Fujioka-Kobayashi M, Zhang Y, Kawase T, Cosgarea R, Jepsen S, Bishara M, Canullo L, Shirakata Y, Gruber R, Ferenc D, Calasans-Maia MD, Wang HL, Sculean A (2021) Use of platelet-rich fibrin for the treatment of periodontal intrabony defects: a systematic review and meta-analysis. Clin Oral Investig. https://doi.org/10.1007/s00784-021-03825-8

10. Cagetti MG, Wolf TG, Tennert C, Camoni N, Lingström P, Campus G (2020) The role of vitamins in oral health. A systematic review and meta-analysis. Int J Environ Res Public Health 17(3). https://doi.org/10.3390/ijerph17030938

11. Tada A, Miura H (2019) The relationship between vitamin $\mathrm{c}$ and periodontal diseases: a systematic review. Int J Environ Res Public Health 16(14). https://doi.org/10.3390/ijerph16142472

12. Abou Sulaiman AE, Shehadeh RM (2010) Assessment of total antioxidant capacity and the use of vitamin $\mathrm{C}$ in the treatment of non-smokers with chronic periodontitis. J Periodontol 81(11): 1547-1554. https://doi.org/10.1902/jop.2010.100173

13. Wei F, Qu C, Song T, Ding G, Fan Z, Liu D, Liu Y, Zhang C, Shi S, Wang S (2012) Vitamin C treatment promotes mesenchymal stem cell sheet formation and tissue regeneration by elevating telomerase activity. J Cell Physiol 227(9):3216-3224. https://doi.org/10.1002/jcp.24012

14. Yang Y, Wang T, Zhang S, Jia S, Chen H, Duan Y, Wang S, Chen G, Tian W (2021) Vitamin C alleviates the senescence of periodontal ligament stem cells through inhibition of Notch3 during longterm culture. J Cell Physiol 236(2):1237-1251

15. Huang Y, Tang X, Xie W, Zhou Y, Li D, Zhu J, Yuan T, Lai L, Pang D, Ouyang H (2011) Vitamin C enhances in vitro and in vivo development of porcine somatic cell nuclear transfer embryos. Biochem Biophys Res Commun 411(2):397-401. https://doi.org/ 10.1016/j.bbrc.2011.06.160

16. Van Pham P, Tran NY, Phan NL-C, Vu NB, Phan NK (2016) Vitamin $\mathrm{C}$ stimulates human gingival stem cell proliferation and expression of pluripotent markers. In Vitro Cellular \& Developmental Biology-Animal 52(2):218-227

17. Fawzy El-Sayed KM, Nguyen N, Dorfer CE (2020) Ascorbic acid, inflammatory cytokines (IL- $1 \beta / \mathrm{TNF}-\alpha / \mathrm{IFN}-\gamma$ ), or their combination's effect on stemness, proliferation, and differentiation of gingival mesenchymal stem/progenitor cells. Stem Cells Int 2020, 1, 14

18. Tonetti MS, Greenwell H, Kornman KS (2018) Staging and grading of periodontitis: framework and proposal of a new classification and case definition. J Periodontol 89(Suppl 1):S159-S172. https:// doi.org/10.1002/JPER.18-0006 
19. Tonetti MS, Sanz M (2019) Implementation of the new classification of periodontal diseases: decision-making algorithms for clinical practice and education. J Clin Periodontol 46(4):398-405. https://doi.org/10.1111/jcpe.13104

20. Lekovic V, Milinkovic I, Aleksic Z, Jankovic S, Stankovic P, Kenney EB, Camargo PM (2012) Platelet-rich fibrin and bovine porous bone mineral vs. platelet-rich fibrin in the treatment of intrabony periodontal defects. J Periodontal Res 47(4):409-417. https://doi.org/10.1111/j.1600-0765.2011.01446.x

21. Ramfjord SP (1967) The periodontal disease index (PDI).

22. Francetti L, Del Fabbro M, Basso M, Testori T, Weinstein R (2004) Enamel matrix proteins in the treatment of intra-bony defects. A prospective 24-month clinical trial. J Clin Periodontol 31(1):52-59. https://doi.org/10.1111/j.0303-6979.2004.00437.x

23. Tonetti MS, Pini-Prato G, Cortellini P (1993) Periodontal regeneration of human intrabony defects. IV. Determinants of healing response. J Periodontol 64(10):934-940. https://doi.org/10.1902/jop. 1993.64.10.934

24. O'Leary TJ (1986) The impact of research on scaling and root planning. J Periodontol 57(2):69-75. https://doi.org/10.1902/jop. 1986.57.2.69

25. Tsitoura E, Tucker R, Suvan J, Laurell L, Cortellini P, Tonetti M (2004) Baseline radiographic defect angle of the intrabony defect as a prognostic indicator in regenerative periodontal surgery with enamel matrix derivative. J Clin Periodontol 31(8):643-647. https://doi.org/10.1111/j.1600-051X.2004.00555.x

26. Aydemir Turkal H, Demirer S, Dolgun A, Keceli HG (2016) Evaluation of the adjunctive effect of platelet-rich fibrin to enamel matrix derivative in the treatment of intrabony defects. Six-month results of a randomized, split-mouth, controlled clinical study. J Clin Periodontol 43(11):955-964. https://doi.org/10.1111/jcpe.12598

27. Górski B, Jalowski S, Górska R, Zaremba M (2019) Treatment of intrabony defects with modified perforated membranes in aggressive periodontitis: subtraction radiography outcomes, prognostic variables, and patient morbidity. Clin Oral Investig 23(7):30053020. https://doi.org/10.1007/s00784-018-2712-7

28. Sanz M, Herrera D, Kebschull M, Chapple I, Jepsen S, Beglundh T, Sculean A, Tonetti MS, Consultants EWPaM (2020) Treatment of stage I-III periodontitis-The EFP S3 level clinical practice guideline. J Clin Periodontol 47(Suppl 22):4-60. https://doi.org/10.1111/ jcpe. 13290

29. Graziani F, Karapetsa D, Mardas N, Leow N, Donos N (2018) Surgical treatment of the residual periodontal pocket. Periodontol 2000 76(1):150-163. https://doi.org/10.1111/prd.12156

30. Polak D, Clemer-Shamai N, Shapira L (2019) Incorporating antibiotics into platelet-rich fibrin: a novel antibiotics slow-release biological device. J Clin Periodontol 46(2):241-247. https://doi.org/ $10.1111 /$ jcpe. 13063

31. Dohan DM, Choukroun J, Diss A, Dohan SL, Dohan AJ, Mouhyi J, Gogly B (2006) Platelet-rich fibrin (PRF): a second-generation platelet concentrate. Part II: platelet-related biologic features. Oral Surg Oral Med Oral Pathol Oral Radiol Endod 101(3):e45-e50

32. Ferrarotti F, Romano F, Gamba MN, Quirico A, Giraudi M, Audagna M, Aimetti M (2018) Human intrabony defect regeneration with micrografts containing dental pulp stem cells: a randomized controlled clinical trial. J Clin Periodontol 45(7):841-850. https://doi.org/10.1111/jcpe.12931

33. Aslan S, Buduneli N, Cortellini P (2020) Clinical outcomes of the entire papilla preservation technique with and without biomaterials in the treatment of isolated intrabony defects: a randomized controlled clinical trial. J Clin Periodontol 47(4):470-478. https://doi. org/10.1111/jcpe. 13255

34. Papapanou PN, Tonetti MS (2000) Diagnosis and epidemiology of periodontal osseous lesions. Periodontol 22:8-21. https://doi.org/ 10.1034/j.1600-0757.2000.2220102.x
35. Shukla S, Chug A, Mahesh L, Singh S, Singh K (2019) Optimal management of intrabony defects: current insights. Clin Cosmet Investig Dent 11:19-25. https://doi.org/10.2147/CCIDE.S166164

36. Sculean A, Nikolidakis D, Nikou G, Ivanovic A, Chapple IL, Stavropoulos A (2015) Biomaterials for promoting periodontal regeneration in human intrabony defects: a systematic review. Periodontol 2000 68(1):182-216. https://doi.org/10.1111/prd.12086

37. Caffesse RG, Sweeney PL, Smith BA (1986) Scaling and root planning with and without periodontal flap surgery. J Clin Periodontol 13(3):205-210. https://doi.org/10.1111/j.1600-051x. 1986.tb01461.x

38. Ramfjord SP, Nissle RR (1974) The modified widman flap. J Periodontol 45(8):601-607. https://doi.org/10.1902/jop.1974.45.8.2.601

39. Petsos H, Ratka-Krüger P, Neukranz E, Raetzke P, Eickholz P, Nickles K (2019) Infrabony defects 20 years after open flap debridement and guided tissue regeneration. $\mathrm{J}$ Clin Periodontol 46(5):552-563. https://doi.org/10.1111/jcpe. 13110

40. Needleman I, Tucker R, Giedrys-Leeper E, Worthington H (2005) Guided tissue regeneration for periodontal intrabony defects-a Cochrane systematic review. Periodontol 37:106-123. https://doi. org/10.1111/j.1600-0757.2004.37101.x

41. Cortellini P, Tonetti MS (2000) Focus on intrabony defects: guided tissue regeneration. Periodontol 22:104-132. https://doi.org/10. 1034/j.1600-0757.2000.2220108.x

42. Nibali L, Sultan D, Arena C, Pelekos G, Lin GH, Tonetti M (2021) Periodontal infrabony defects: systematic review of healing by defect morphology following regenerative surgery. J Clin Periodontol 48(1):100-113. https://doi.org/10.1111/jcpe.13381

43. Kanoriya D, Pradeep AR, Singhal S, Garg V, Guruprasad CN (2016) Synergistic approach using platelet-rich fibrin and 1\% alendronate for intrabony defect treatment in chronic periodontitis: a randomized clinical trial. J Periodontol 87(12):1427-1435. https://doi.org/10.1902/jop.2016.150698

44. Martande SS, Kumari M, Pradeep AR, Singh SP, Suke DK, Guruprasad CN (2016) Platelet-rich fibrin combined with 1.2\% atorvastatin for treatment of intrabony defects in chronic periodontitis: a randomized controlled clinical trial. J Periodontol 87(9): 1039-1046. https://doi.org/10.1902/jop.2016.150306

45. Pradeep AR, Garg V, Kanoriya D, Singhal S (2016) Platelet-rich fibrin with $1.2 \%$ rosuvastatin for treatment of intrabony defects in chronic periodontitis: a randomized controlled clinical trial. J Periodontol 87(12):1468-1473. https://doi.org/10.1902/jop.2016.160015

46. Pradeep AR, Karvekar S, Nagpal K, Patnaik K, Raju A, Singh P (2016) Rosuvastatin $1.2 \mathrm{mg}$ in situ gel combined with 1:1 mixture of autologous platelet-rich fibrin and porous hydroxyapatite bone graft in surgical treatment of mandibular class II furcation defects: a randomized clinical control trial. J Periodontol 87(1):5-13. https:// doi.org/10.1902/jop.2015.150131

47. Pradeep AR, Nagpal K, Karvekar S, Patnaik K, Naik SB, Guruprasad CN (2015) Platelet-rich fibrin with 1\% metformin for the treatment of intrabony defects in chronic periodontitis: a randomized controlled clinical trial. J Periodontol 86(6):729-737. https://doi.org/10.1902/jop.2015.140646

48. Bansal C, Bharti V (2013) Evaluation of efficacy of autologous platelet-rich fibrin with demineralized-freeze dried bone allograft in the treatment of periodontal intrabony defects. Journal of Indian Society of Periodontology 17(3):361-366. https://doi.org/ 10.4103/0972-124X.115663

49. Shah M, Patel J, Dave D, Shah S (2015) Comparative evaluation of platelet-rich fibrin with demineralized freeze-dried bone allograft in periodontal infrabony defects: a randomized controlled clinical study. Journal of Indian Society of Periodontology 19(1):56-60. https://doi.org/10.4103/0972-124X.145803

50. Sezgin Y, Uraz A, Taner IL, Culhaoglu R (2017) Effects of plateletrich fibrin on healing of intra-bony defects treated with anorganic 
bovine bone mineral. Braz Oral Res 31:e15. https://doi.org/10. 1590/1807-3107BOR-2017.vol31.0015

51. Mathur A, Bains VK, Gupta V, Jhingran R, Singh GP (2015) Evaluation of intrabony defects treated with platelet-rich fibrin or autogenous bone graft: a comparative analysis. Eur J Dent 9(1): 100-108. https://doi.org/10.4103/1305-7456.149653

52. Gupta SJ, Jhingran R, Gupta V, Bains VK, Madan R, Rizvi I (2014) Efficacy of platelet-rich fibrin vs. enamel matrix derivative in the treatment of periodontal intrabony defects: a clinical and cone beam computed tomography study. J Int Acad Periodontol 16(3):86-96

53. Chadwick JK, Mills MP, Mealey BL (2016) Clinical and radiographic evaluation of demineralized freeze-dried bone allograft versus platelet-rich fibrin for the treatment of periodontal intrabony defects in humans. J Periodontol 87(11):1253-1260. https://doi. org/10.1902/jop.2016.160309

54. Bodhare GH, Kolte AP, Kolte RA, Shirke PY (2019) Clinical and radiographic evaluation and comparison of bioactive bone alloplast morsels when used alone and in combination with platelet-rich fibrin in the treatment of periodontal intrabony defects-a randomized controlled trial. J Periodontol 90(6):584-594. https://doi.org/ 10.1002/JPER.18-0416

55. Patel RA, Wilson RF, Palmer RM (2012) The effect of smoking on periodontal bone regeneration: a systematic review and meta-analysis. J Periodontol 83(2):143-155. https://doi.org/10.1902/jop.2011.110130

56. Ramseier CA, Abramson ZR, Jin Q, Giannobile WV (2006) Gene therapeutics for periodontal regenerative medicine. Dent Clin $\mathrm{N}$ Am 50(2):245-263, ix. https://doi.org/10.1016/j.cden.2005.12.001

57. Sood S, Gupta S, Mahendra A (2012) Gene therapy with growth factors for periodontal tissue engineering-a review. Med Oral Patol Oral Cir Bucal 17(2):e301-e310. https://doi.org/10.4317/medoral.17472

58. Fawzy El-Sayed KM, Dorfer CE (2017) (*) Animal models for periodontal tissue engineering: a knowledge-generating process. Tissue Eng Part C Methods 23(12):900-925. https://doi.org/10. 1089/ten.TEC.2017.0130

59. Nurden AT (2011) Platelets, inflammation and tissue regeneration. Thromb Haemost 105(Suppl 1):S13-S33. https://doi.org/10.1160/ THS10-11-0720

60. Gassling VL, Acil Y, Springer IN, Hubert N, Wiltfang J (2009) Platelet-rich plasma and platelet-rich fibrin in human cell culture. Oral Surg Oral Med Oral Pathol Oral Radiol Endod 108(1):48-55. https://doi.org/10.1016/j.tripleo.2009.02.007

61. Miron RJ, Zucchelli G, Pikos MA, Salama M, Lee S, Guillemette V, Fujioka-Kobayashi M, Bishara M, Zhang Y, Wang HL, Chandad F, Nacopoulos C, Simonpieri A, Aalam AA, Felice P, Sammartino G, Ghanaati S, Hernandez MA, Choukroun J (2017) Use of platelet-rich fibrin in regenerative dentistry: a systematic review. Clin Oral Investig 21(6):1913-1927. https://doi.org/10. 1007/s00784-017-2133-z

62. Thorat M, Pradeep AR, Pallavi B (2011) Clinical effect of autologous platelet-rich fibrin in the treatment of intra-bony defects: a controlled clinical trial. J Clin Periodontol 38(10):925-932. https://doi.org/10.1111/j.1600-051X.2011.01760.x

63. Sharma A, Pradeep AR (2011) Treatment of 3-wall intrabony defects in patients with chronic periodontitis with autologous plateletrich fibrin: a randomized controlled clinical trial. J Periodontol 82(12):1705-1712. https://doi.org/10.1902/jop.2011.110075

64. Patel GK, Gaekwad SS, Gujjari SK, S C VK (2017) Platelet-rich fibrin in regeneration of intrabony defects: a randomized controlled trial. J Periodontol 88(11):1192-1199. https://doi.org/10.1902/jop. 2017.130710

65. Chen L, Ding Y, Cheng G, Meng S (2021) Use of platelet-rich fibrin in the treatment of periodontal intrabony defects: a systematic review and meta-analysis. Biomed Res Int 2021:66691686669113. https://doi.org/10.1155/2021/6669168
66. Miron RJ, Zhang Y (2018) Autologous liquid platelet rich fibrin: a novel drug delivery system. Acta Biomater 75:35-51. https://doi. org/10.1016/j.actbio.2018.05.021

67. Verma UP, Yadav RK, Dixit M, Gupta A (2017) Platelet-rich fibrin: a paradigm in periodontal therapy - a systematic review. J Int Soc Prev Community Dent 7(5):227-233. https://doi.org/10.4103/ jispcd.JISPCD_429_16

68. Bi J, Intriago MFB, Koivisto L, Jiang G, Häkkinen L, Larjava H (2020) Leucocyte- and platelet-rich fibrin regulates expression of genes related to early wound healing in human gingival fibroblasts. J Clin Periodontol 47(7):851-862. https://doi.org/10.1111/jcpe. 13293

69. Sato H, Takahashi M, Ise H, Yamada A, Hirose S-i, Tagawa Y-i, Morimoto H, Izawa A, Ikeda U (2006) Collagen synthesis is required for ascorbic acid-enhanced differentiation of mouse embryonic stem cells into cardiomyocytes. Biochem Biophys Res Commun 342(1):107-112

70. Yan Y, Zeng W, Song S, Zhang F, He W, Liang W, Niu Z (2013) Vitamin $\mathrm{C}$ induces periodontal ligament progenitor cell differentiation via activation of ERK pathway mediated by PELP1. Protein Cell 4(8):620-627. https://doi.org/10.1007/s13238-013-3030-0

71. Ishikawa S, Iwasaki K, Komaki M, Ishikawa I (2004) Role of ascorbic acid in periodontal ligament cell differentiation. J Periodontol 75(5): 709-716. https://doi.org/10.1902/jop.2004.75.5.709

72. D'Aniello C, Cermola F, Patriarca EJ, Minchiotti G (2017) Vitamin $\mathrm{C}$ in stem cell biology: impact on extracellular matrix homeostasis and epigenetics. Stem Cells Int 2017:8936156-8936116. https:// doi.org/10.1155/2017/8936156

73. Van der Velden U (2020) Vitamin C and its role in periodontal diseases - the past and the present: a narrative review. Oral Health Prev Dent 18(2):115-124. https://doi.org/10.3290/j.ohpd.a44306

74. Otsuka E, Yamaguchi A, Hirose S, Hagiwara H (1999) Characterization of osteoblastic differentiation of stromal cell line ST2 that is induced by ascorbic acid. Am J Phys 277(1):C132C138. https://doi.org/10.1152/ajpcell.1999.277.1.C132

75. Gauthier P, Yu Z, Tran QT, Bhatti FU, Zhu X, Huang GT (2017) Cementogenic genes in human periodontal ligament stem cells are downregulated in response to osteogenic stimulation while upregulated by vitamin C treatment. Cell Tissue Res 368(1):79-92. https://doi.org/10.1007/s00441-016-2513-8

76. Yussif N, Koranyb N, Abbassc M (2017) Evidence of the effect of intraepidermic vitamin $\mathrm{c}$ injection on melanocytes and keratinocytes in gingival tissues. Vivo

77. Yussif NM, Rahman ARA, ElBarbary A (2019) Minimally invasive non-surgical locally injected vitamin $C$ versus the conventional surgical depigmentation in treatment of gingival hyperpigmentation of the anterior esthetic zone: a prospective comparative study. Clinical Nutrition Experimental 24:54-65

78. Fujioka-Kobayashi M, Kono M, Katagiri H, Schaller B, Zhang Y, Sculean A, Miron RJ (2021) Histological comparison of platelet rich fibrin clots prepared by fixed-angle versus horizontal centrifugation. Platelets 32(3):413-419. https://doi.org/10.1080/09537104. 2020.1754382

79. Miron RJ, Chai J, Zheng S, Feng M, Sculean A, Zhang Y (2019) A novel method for evaluating and quantifying cell types in platelet rich fibrin and an introduction to horizontal centrifugation. J Biomed Mater Res A 107(10):2257-2271. https://doi.org/10. 1002/jbm.a.36734

80. Cortellini P (2000) Tonetti MS (2015) Clinical concepts for regenerative therapy in intrabony defects. Periodontol 68(1):282-307. https://doi.org/10.1111/prd.12048

81. Yuan F-L, Xu M-H, Li X, Xinlong H, Fang W, Dong J (2016) The roles of acidosis in osteoclast biology. Front Physiol 7:222-222. https://doi.org/10.3389/fphys.2016.00222 